\title{
Ideas infantiles sobre la producción de noticias en los medios
}

\section{Childish Ideas About the Production of News in the Media}

Idées des enfants par rapport à la production de nouvelles dans les medias Ideias infantis sobre produção de notícias na mídia

Fecha de recepción: 6 DE FEBRERO DE 2014 / Fecha de aceptación: 6 DE MAYO DE 2015 / Fecha de disponibilidad en línea: 30 DE OCTUBRE DE 2015

Encuentre este artículo en http://magisinvestigacioneducacion.javeriana.edu.co/

\section{Resumen}

Los objetivos de la investigación cualitativa que enmarca este artículo son indagar las ideas infantiles a propósito de la producción de noticias y generar situaciones didácticas que promuevan la lectura crítica de los medios. El foco de este artículo de investigación está en los saberes discursivos y en las líneas de progresión de las conceptualizaciones sobre la producción y circulación de noticias de alumnos de sexto de primaria de la Ciudad de Buenos Aires. Los niños advierten requisitos para que un hecho sea noticia, pero no logran dilucidar que las noticias están sometidas a procesos de selección y elaboración mediáticos.

\section{Palabras clave}

Educación sobre medios de comunicación; discurso;

cognición; lectura

\section{Transferencia a la práctica}

Se espera que esta investigación eche luz sobre conceptos y representaciones de niños y jóvenes sobre la producción de noticias para ayudar a diseñar situaciones didácticas que les permitan superar una lectura ingenua de los medios. Por ejemplo, al promover la discusión sobre aspectos invisibilizados en la producción de noticias (selección y edición), las formas de tratamiento de los hechos y los puntos de vista asumidos. Asimismo, se busca plantear caminos de progresión, durante la escolaridad, de contenidos y modos de reflexión sobre el discurso de los medios que operen sobre estas ideas.
Escrito por Flora Perelman Universidad de Buenos Aires, UBA Buenos Aires, Argentina fperelma@arnet.com.ar

DÉbORA NAKACHE Universidad de Buenos Aires, UBA Buenos Aires, Argentina debynakache@hotmail.com

GabRIELA RubINOVICH Universidad de Buenos Aires, UBA Buenos Aires, Argentina gabyrubinovich@gmail.com

María Elena Rodríguez Universidad Nacional de La Plata, UNLP Buenos Aires, Argentina merodriguez47@gmail.com

María Jimena Dib Escuela de Capacitación Docente Buenos Aires, Argentina jimena.dib@gmail.com

Para citar este artículo / To cite this article / Pour citer cet article / Para citar este artigo Perelman, F.; Nakache, D.; Rubinovich, G.; Rodríguez. M. E. \& Dib, M. J. (2015). Ideas infantiles sobre la producción de noticias en los medios. magis, Revista Internacional de Investigación en Educación, 8(16), 13-32. http://dx.doi.org/10.11144/Javeriana.m8-16.iipn 


\section{Keywords}

Media education; speech;

cognition; reading

\section{Abstract}

This article, of qualitative nature, aims to investigate the ideas of children regarding news production and generate didactic situations that promote critical reading of the media. This paper focuses on the discursive knowledges and lines of progression of the conceptualizations regarding production and circulation of news of sixth grade students from the City of Buenos Aires. Children notice the requirements for a fact to be newsworthy, but fail to elucidate that news are subjected to selection processes and media development.

\section{Transfer to practice}

This research is expected to shed light on concepts and representations of children and youth regarding the production of news, in order to help design teaching situations that allow them to overcome a naive reading of media. For example, by promoting discussion on invisible issues in news production (selection and edition), and the ways of treating the facts and points of view. It also seeks to raise progression paths, during schooling, of contents and ways of reflection on the media discourse that operate on these ideas.

\section{Mots clés}

Education sur les medias de communication; discours; cognition; lecture

\section{Résumé}

Les objectifs de la recherche qualitative qui encadrent cet article sont chercher dans les idées des enfants à propos de la pro duction de nouvelles et produire situations didactiques pour promouvoir la lecture critique des medias. L'intérêt de cet article de recherche est dans les savoirs discursifs et dans les lignes de progression des conceptualisations sur la production et circulation de nouvelles d'élèves de sixième de la ville de Buenos Aires. Les enfants préviennent sur les conditions pour qu'un fait soit considéré comme nouvelle dans les medias, mais ils n'arrivent pas à élucider que les nouvelles sont traités à processus de choix et élaboration médiatique.

\section{Transfert à la pratique}

On attend que cette recherche projette une lumière sur les concepts et les représentations des enfants et des jeunes par rapport à la production de nouvelles pour de cette façon aider à dessiner des situations didactiques dans lesquelles ils puissent dépasser une lecture naïve des medias. Par exemple, lorsqu'on encourage le débat sur les aspects rendus invisibles dans la production de nouvelles (le choix et l'édition), les façons de traitement des faits et les points de vue qu'on assume. Ainsi, on cherche proposer de chemins de progression, pendant la scolarité, de contenus et moyens de réflexions par rapport au discours des medias qui opèrent sur ces idées.

\section{Palavras-chave}

Ensino sobre mídia; discurso; cognição; leitura

\section{Resumo}

Os objetivos da pesquisa qualitativa que enquadra este artigo são indagar pelas ideias infantis a propósito da produção de notícias e gerar situações didáticas que promovam a leitura crítica da mídia. O foco deste artigo de pesquisa está nos saberes discursivos e nas linhas de progressão das conceptualizações sobre produção e circulação de notícias de alunos de sexto de primaria da Cidade de Buenos Aires. As crianças advertem requisitos para um fato ser notícia, mas não conseguem dilucidar que as notícias são sometidas a processos de seleção e elaboração mediáticos.

\section{Transferência à prática}

Espera-se que esta pesquisa lance luz sobre conceitos e representações de crianças e jovens sobre a produção de notícias para ajudar a desenhar situações didáticas que Ihes permitirem superar uma leitura ingênua da mídia. Por exemplo, ao promover a discussão sobre aspectos invisibilizados na produção de notícias (seleção e edição), as formas de tratamento dos fatos e pontos de vista assumidos. Mesmo assim, visa-se colocar caminhos de progressão durante a escolaridade, de conteúdos e modos de reflexão sobre o discurso da mídia que operem sobre estas ideias. 


\section{Introducción}

El propósito de este artículo es presentar el análisis de las conceptualizaciones de alumnos de sexto grado acerca de las noticias y sus procesos de circulación y producción. Este análisis forma parte de la primera etapa de una investigación ${ }^{1}$ que se propone inicialmente indagar las conceptualizaciones infantiles sobre el proceso de producción de noticias y en una segunda etapa, explorar situaciones didácticas que posibiliten la lectura crítica de los mensajes noticiosos.

El estudio crítico de la noticia supone visibilizar las condiciones y los mecanismos de selección y producción del verosímil que crean las empresas para posicionarse en el mercado mediático. Leer críticamente un discurso informativo implica saber que los textos que se están leyendo, lejos de ser un fiel reflejo de los acontecimientos que transmiten, representan una construcción de la realidad producida por un autor individual o colectivo en el marco de una situación determinada. Este conocimiento es neurálgico tanto para la interpretación de los discursos de las ciencias como para el acercamiento a las noticias mediáticas que circulan en cualquier soporte, sea papel o pantalla u otro dispositivo multimedia.

En esta investigación se han tenido en cuenta diversas perspectivas de análisis - comunicacional, discursiva, psicoeducativa y didáctica - íntimamente relacionadas a lo largo del proceso de indagación. En cada una de ellas, apelamos a tradiciones de investigación diferentes pero consistentes entre sí ya que comparten presupuestos epistemológicos de base que las hacen compatibles (Perelman \& Nakache, 2011).

A continuación, haremos una muy breve referencia a las perspectivas mencionadas que guiaron nuestro análisis de las conceptualizaciones infantiles.

\section{Perspectiva comunicacional}

Desde esta perspectiva, intentamos observar de qué manera los niños se acercan a los medios de comunicación, teniendo en cuenta que estos medios son organizaciones instituidas de la sociedad que, como todas las demás existentes, poseen sus propias reglas de funcionamiento, sus dinámicas de producción, circulación y consumo; y, a la vez, un mandato social (Williams, 1977).

En el mundo mediatizado que habitamos resulta necesario entonces comprender que la televisión, la prensa, la radio o internet configuran los soportes por medio de los cuales los sujetos nos informamos, nos entretenemos y socializamos. Estos medios imbricados, convergentes y vinculados entre sí pertenecen a determinados grupos de poder que están íntimamente relacionados con otros espacios dentro del campo social (Mastrini \& Becerra, 2006), tanto local como trasnacional. Cada grupo de medios transmite una visión particular del mundo mediante todos los productos culturales que ofrece a la comunidad.

Este "punto de vista" que los medios nos ofrecen es el producto de un proceso variado de construcción de un determinado discurso mediático

\footnotetext{
Descripción del artículo | Article description | Description de l'article | Artigo descrição

Este artículo forma parte de la investigación Lectura crítica de noticias: conceptualizaciones de niños y jóvenes en situaciones didácticas. Se propone abordar el análisis de las conceptualizaciones de alumnos de sexto grado acerca de las noticias y sus procesos de circulación y producción a partir de diversas perspectivas de análisis - comunicacional, discursiva, psicoeducativa y didáctica-, íntimamente relacionadas durante el proceso de indagación.
}

1 Proyecto trienal consolidado Lectura crítica de noticias: conceptualizaciones de niños y jóvenes en situaciones didácticas, aprobado y subsidiado por la Secretaría de Ciencia y Técnica de la Universidad de Buenos Aires para el período 2013-2016. Facultad de Psicología, Cátedras de Psicología y Epistemología Genética I y Psicología Educacional I. Directora: Flora Perelman. Codirectora: Débora Nakache. Integrantes: Patricio Román Bertacchini, Silvana Díaz, Jimena Dib, Vanina Estévez, Olga López-Broggi, Mariana Ornique, María Elena Rodríguez y Gabriela Rubinovich. 
que no se sustrae a la lógica de funcionamiento de la cultura hegemónica (Williams, 1977), en la que los intereses de ciertos sectores sociales se van constituyendo en los intereses de toda la sociedad. De modo que, sin asumir una postura ni "apocalíptica ni integrada" (Eco, 1965), es imprescindible considerar que los medios de comunicación en esta cultura de masas responden a ciertos intereses que son los que perfilan los tipos de discursos que se acercan a la sociedad y que generan la eterna tensión entre los intereses de los dueños de los medios y los de las audiencias. En este sentido resulta valioso el concepto de 'encuadre' de las noticias (framing) que, para diversos autores (Aruguete \& Zunino, 2010), atraviesa todo el proceso comunicacional (el comunicador, el texto, el receptor y la cultura). Stephen D. Reese (2001) define el encuadre como los "principios organizadores socialmente compartidos y persistentes en el tiempo, que trabajan simbólicamente para estructurar el mundo social de modo significativo" (p. 11). Encuadrar supone que cada medio provee una forma de pensar los eventos. Se trata de un amplio proceso que cada uno de los medios desarrolla cuyo funcionamiento se pone en evidencia en la instancia de elaboración y tratamiento de las noticias, en las huellas que deja en los mensajes noticiosos y en el tipo de efectos que genera en la recepción por parte de la audiencia en la medida en que todos están en el mismo contexto cultural. En la práctica, todos los medios periodísticos, en sus diferentes soportes, operan de diversas maneras tanto para el establecimiento de agendas temáticas (aquello sobre lo que la gente hablará) como para el silenciamiento de determinados temas (Agenda Cutting).

Hoy es imprescindible considerar, además, que la irrupción y el rápido avance de las tecnologías infocomunicacionales en el ámbito del periodismo operan sobre la producción y circulación de las noticias y también sobre la recepción. Todos los actores involucrados en el proceso informativo mutaron sus posiciones y la profesión se modificó al cambiar los modos de producción de dicho discurso (Luchessi, 2010). En el nuevo escenario se instaló la instantaneidad, el estar ahí, el ser testigo, como criterio central de las noticias y, de algún modo, la información comenzó a ser reticular, lo cual permite la construcción de un entramado en el que el propio sistema mediático se retroalimenta (diarios, televisión, internet, etc.), tanto para la producción como para la circulación de la información. Mientras que en épocas pasadas los periodistas eran los encargados de investigar, agotar variedades de fuentes informativas, presentar muchas voces en pantalla, en la actualidad los mecanismos de validación de las informaciones resultan ser mucho más volátiles y, a la vez, unívocos. El chequeo con otros medios, el discurso autorreferencial, la competencia y la desvalorización de ciertas primicias convergen en el establecimiento de agendas unívocas. Esto se observa claramente al encender el televisor y confirmar, luego de un zapping, que todos los canales dan la misma data o abordan los mismos temas.

En cuanto a la producción del discurso informativo, podemos distinguir tres procesos:

En primer lugar, todos los medios seleccionan y producen, desde un determinado punto de vista, aquella información que darán a conocer y aquellos contenidos que abordarán. Este proceso de selección es imprescindible, dado que sería imposible publicar todo lo que sucede en el mundo a lo largo de un día (pensando en la edición diaria de un periódico, por ejemplo). La selección se realiza de acuerdo con la línea editorial, los intereses particulares y el público al que desea dirigirse. El lector accede, por lo tanto, a una cantidad de información que el medio ha seleccionado previamente por y para él. Actualmente, con alta frecuencia, esta información proviene de agencias y de cadenas de noticias con base e impronta capitalina o multinacional. Esto cambia el eje de qué es noticia y cuáles son los sucesos noticiables dado que se modifica la escala de lo observado (¿es un hecho de interés particular, local, global?). Por eso, muchas veces lo noticiable dista mucho de los intereses y/ necesidades del grupo al que pertenecemos, aunque se nos impone como una mercancía incuestionable.

En segundo lugar, una vez seleccionada la información que se dará a la opinión pública como actualidad informativa, el medio realiza su jerarquización. La ubicación de las noticias dentro del periódico, del noticiero o la página web explica la prioridad informativa del medio respecto de los temas. No resulta lo mismo que una nota aparezca en la tapa de un diario o que esté en página par o impar, en la 3 o la 13.

Y finalmente, todo medio de comunicación masiva desarrolla un particular tratamiento de la información que seleccionó y jerarquizó para darle difusión. En esta instancia, el medio bosqueja su propio perfil. En las salas de redacción/producción del medio, se definen lenguajes, géneros, tomas de cámara, tipos de entrevistas. Se pone allí en evidencia una decisión que se pensó y se discutió previamente sobre cómo construir, de cierto modo y no de otro, ese hecho que se determinó que es importante. Por lo tanto, cuando se habla del tratamiento de la información que desarrolla un medio, se piensa no solo en el modo de titular una nota (tamaño de tipografía) sino también en qué espacio ocupa, ¿es acompañada de una infografía o una fotografía?, ise publica alguna entrevista respecto del tema? y finalmente, ¿cómo se redactó esa noticia?, ¿aparece una crónica o una nota de un especialista o ambas cosas?

Todo esto constituye una parte fundamental del proceso de producción de la información que los 
medios realizan de acuerdo con los intereses, los puntos de vista, las decisiones editoriales de quienes los representan. Es interesante señalar que este proceso de producción del discurso informativo nos llega a nosotros acabado y en excelentes condiciones para su recepción, es decir, hay un producto final que de algún modo borra, invisibiliza, toda su producción.

\section{Perspectiva discursiva}

El análisis acerca de los saberes discursivos de los niños sobre la noticia, como uno de los géneros centrales del discurso de los medios de comunicación social, se ubica, primordialmente, en el amplio campo del análisis del discurso desde la perspectiva de Patrick Charaudeau (2003) y del enfoque multidisciplinario del análisis crítico del discurso representado por Teun van Dijk y colaboradores (Van Dijk, 1999, 2000, 2003; Wodak \& Meyer, 2003).

Tomamos en cuenta que la comunicación mediática sienta sus bases en un contrato entre una instancia de producción y una instancia de recepción que se ejecuta en el marco de determinadas condiciones situacionales políticas, económicas y culturales. Este contrato refleja una tensión constante entre el propósito de informar al ciudadano y el de persuadirlo. Es decir, los medios están requeridos por una doble demanda. Por un lado, como organismos especializados en transmitir información, están al servicio de la ciudadanía a la cual deben hacer conocer, de la manera más transparente posible, lo que acontece en el espacio público. Por otro, como empresas que compiten en un mismo mercado, deben captar a la audiencia desde una lógica económica, que obliga a la publicación:

(...) a utilizar recursos de seducción que no siempre están de acuerdo con la exigencia de credibilidad que le asigna su función de servicio ciudadano; sin contar que, a causa de que la información se ocupa de los acontecimientos del espacio público político y civil, no siempre quedará exenta de una toma de posición ideológica (Charaudeau, 2003, p. 72).

Tomar conciencia de esta tensión permite ahondar en la complejidad de la relación entre los hechos y el relato mediático.

Consideramos, entonces, que el discurso mediático no constituye un fiel reflejo de los acontecimientos que transmite el medio, sino que detrás de este discurso hay un enunciador, individual o colectivo, situado en un lugar y en un momento concretos, con una determinada visión de la realidad inextricablemente unida a sus intenciones, valores y actitudes (Cassany, 2006).

Entre los hechos y el discurso acerca de los hechos tiene lugar un doble proceso de transformación y de transacción. El primero, que se vincula primordialmente con la instancia de producción, consiste en una serie de operaciones que dan visibilidad y significación al acontecimiento "en bruto" para convertirlo en noticia, operaciones como seleccionar los hechos, mencionarlos, describirlos, jerarquizarlos, ubicarlos dentro de un contexto de referencia, comentarlos, explicarlos, etc. El segundo proceso, el de transacción, trae al centro de la escena la instancia receptora en la medida en que el receptor tiene, por un lado, una incidencia decisiva, en las estrategias que usa la instancia de producción para informarle los acontecimientos, y, a la vez, "captarlo", "seducirlo" y, por otro, al interpretar la noticia, el receptor coopera activamente, en la construcción del sentido de ese discurso mediático. Ambos procesos — transformación y transacciónse presentan en un constante interjuego. Cabe subrayar, en relación con 
lo enunciado, que los efectos buscados por el emisor nunca coinciden plenamente con los efectos obtenidos en el receptor.

\section{Perspectiva psicoeducativa}

Cuando focalizamos en la dimensión psicoeducativa, tratamos de comprender los procesos de significación que los sujetos asumen frente al objeto investigado. A partir de la consideración de las especificidades del objeto, en este caso de las noticias mediáticas, en su doble presentación -la que proviene del campo de las teorías comunicacionales y la que las conceptualiza en términos de las teorías del discurso-, esta mirada intenta reconstruir la actividad de los sujetos en interacción con las noticias mediáticas.

En esta aproximación al problema, apelamos a la tradición sociohistórica vigotskiana y al constructivismo relacional piagetiano para dilucidar las conceptualizaciones infantiles involucradas en la interpretación de las noticias y su variación, según el capital cultural y las prácticas sociales en las que los niños participan (Perelman, Nakache \& Estévez, 2012). Asumimos entonces, la relevancia de estas prácticas sociales en la medida en que entraman los procesos de aprendizaje y desarrollo infantiles, en los cuales medios y pantallas constituyen los artefactos de mediación cultural más frecuentados por los sujetos en su cotidianeidad. En la actividad con estos instrumentos los sujetos se apropian de saberes relevantes para su despliegue en el mundo social actual. Desde el constructivismo relacional, tal apropiación implica aproximaciones recursivas a estos objetos complejos que, como producto de una historia colectiva, implican un proceso interactivo en el cual puedan reconstruirse las significaciones que se fueron elaborando a lo largo de ese proceso histórico social de configuración (Piaget \& García, 1982). Los procesos de construcción de conocimientos sociales (como las noticias) han sido estudiados a lo largo de la tradición psicogenética pero requieren cierta especificidad, debido a que los objetos sociales nos constituyen como sujetos, por tanto resultan más difíciles que en el caso de los objetos físicos, los procesos de objetivación necesarios en su construcción. Así podemos afirmar que "los conceptos infantiles se elaboran modulados por las prácticas sociales, que son indisociables de la transmisión de creencias sociales que las expresan y a las que se dirigen" (Castorina, 2010, p. 169). En el caso de las noticias mediáticas, comprender su significado implica para el sujeto un esfuerzo de distanciamiento de un objeto que lo tiene como "blanco" de su acción y que permanentemente configura los modos de entender lo actual y de atribuir criterios de validación de la información (Perelman, Nakache \& Estévez, 2012). Por ello para los sujetos resulta sumamente dificultoso abstraer las propiedades de un noticiero, por ejemplo, pensando en los procesos de su montaje, cuando el propio programa enfatiza que es "en vivo" y que muestra "eso que está sucediendo en el lugar". Desde esta perspectiva, el sujeto está mediado por los medios y gran parte de las limitaciones que tiene para asumir una posición crítica frente a ellos es provocada por la manera en que la propia industria mediática tiene de presentarse y autoafirmarse. Por ello, en el proceso de significación y comprensión del artefacto mediático, nos encontramos con diversos tipos de ideas que coexisten al intentar reconstruir cognitivamente esta trama social que señala las novedades de nuestra época a la hora de organizar los flujos informativos. Debemos apelar, entonces, al concepto de "polifasia cognitiva" acuñado inicialmente por Serge Moscovici (1961), desde la psicología social y que ha sido ampliado por los investigadores que estudian los conocimientos sociales desde la perspectiva de la psicología genética crítica. En la polifasia cognitiva, conviven el sentido común propio de las representaciones sociales y los saberes disciplinares, tal como lo postulan los psicólogos sociales, pero también las conceptualizaciones que construyen los niños ante un objeto sumamente complejo, como el sistema productivo de noticias mediáticas.

\section{Perspectiva didáctica}

Desde esta mirada, buscamos generar conocimiento didáctico sobre la enseñanza de la lectura crítica de los medios. Este conocimiento se refiere a la progresión de los saberes dados y determinados, propósito de enseñanza que la escuela se responsabiliza de promover; al diseño de situaciones de lectura y discusión que se consideren óptimas para la comunicación de esos saberes; a las intervenciones del docente en esas situaciones; a las distintas formas de organización de la clase y su relación con lo que se quiere enseñar; y a la evaluación de la situación y de lo que aprenden los alumnos.

Compartimos con Mirta Castedo que:

(...) el conocimiento didáctico tiene un propósito micropolítico en tanto se preocupa por encontrar las formas de comunicación que aseguren que la mayor cantidad de alumnos acceda al poder de la palabra dicha y escrita, y en tanto se debaten permanentemente las razones y las consecuencias profundas de la imposibilidad de lograrlo (Castedo, 2007, p. 9).

Es decir, desde esta perspectiva hay una fuerte apuesta a la necesidad de generar condiciones de enseñanza propicias, en este caso, para la emergencia de lectores críticos. Por ello, asumimos una concepción de lectura como práctica sociocultural. En este sentido, la lectura es un acto de transacción (Rosenblatt, 2002) 
entre el lector y el texto. Los sentidos se construyen en esa transacción y en la confrontación con otros lectores. No están ni en el texto ni en el lector solamente. El foco en las prácticas de lectura y no en los textos tiene un impacto importante en el modo de concebir la planificación de la enseñanza, pues lleva a poner en primer plano lo que hacen los lectores y hablantes cuando interactúan con los textos y no las características de estos (por ejemplo, las partes de la noticia), y también conduce a valorar los aspectos sociales de esta interacción por encima de las determinaciones individuales y procesuales. ¿Cómo se interpretan las noticias en una comunidad de lectores? es una de las preguntas que queremos dilucidar desde esta perspectiva.

Asimismo, es preciso ampliar el concepto de lectura para abarcar el trabajo con las imágenes y otros lenguajes del mundo audiovisual, pues el acercamiento crítico a las noticias en los medios no se agota en la lectura de la prensa escrita. La convergencia de medios en la actualidad y las mismas prácticas de los consumidores nos exigen repensar las propuestas de enseñanza para atender a la omnipresencia de las pantallas y aprovecharlas en las situaciones de interpretación.

Finalmente, una mirada didáctica de la lectura crítica de los medios en la escuela se preocupa por conocer cuáles son las situaciones que promueven de mejor manera la reflexión de los alumnos, ya sea sobre las propias prácticas por ser relaciones de recepción-interpretación de los medios, o sobre las condiciones de producción y circulación de las noticias en nuestra sociedad y en su variación sociohistórica.

\section{Metodología}

La metodología de la primera etapa consiste en un estudio exploratorio dirigido a indagar las conceptualizaciones infantiles sobre la producción de noticias mediáticas de alumnos de tercero a séptimo grado de escuelas primarias públicas que participan del programa Medios en la Escuela y de escuelas privadas del gobierno de la ciudad de Buenos Aires. Se utilizaron tres instrumentos de obtención de datos: 1) dibujos individuales y grupales con la consigna: "dibujen cómo piensan que se producen las noticias" y "explíquenlo brevemente por escrito", 2) observaciones de aula de las situaciones de producción grupal y de puesta en común colectiva de los dibujos, y 3) entrevistas clínicas individuales. A lo largo de la investigación, se recolectaron 215 dibujos individuales, 29 grupales, 14 observaciones de aula y 6 entrevistas clínicas.

La elección metodológica tiene diversas vertientes. Por un lado, la administración de dibujos individuales fue utilizada tanto por los psicólogos sociales como por los psicólogos piagetianos. Entre los primeros, es relevante la clásica investigación realizada por Annamaria Silvana de Rosa (1987), quien solicitó a niños de distintas edades que dibujasen "locos" y "personas normales" con el propósito de estudiar sus representaciones sociales sobre la enfermedad ${ }^{2}$. En cuanto a los segundos, ya Jean Piaget usó esta técnica en su libro La representación del mundo en el niño (1926) en el estudio sobre los sueños; Emiliana Villaoslada (1997) la empleó para investigar las ideas infantiles sobre la riqueza, la pobreza y la desigualdad social e Irene Daniela Murià-Vila (1995) la utilizó en su indagación sobre las concepciones acerca de Dios. Los investigadores señalan que una de las ventajas de los dibujos es que los niños con frecuencia son capaces de

2 En esta investigación, los dibujos infantiles producidos resultaron notoriamente similares a los estereotipos históricos. 
expresar gráficamente modos de representarse el mundo social que no aparecen en los interrogatorios puramente verbales (Delval, 2001).

Por otro lado, el pedido de una producción individual para luego solicitar su confrontación con el objetivo de realizar una construcción grupal fue probado en investigaciones psicológicas (Gilly, 1988; Perret-Clermont, 1984; Teberosky, 1982) y didácticas (García-Debanc, Laurent \& Galaup, 2009). En las primeras, se analizan las interacciones sociocognitivas como promotoras de perturbaciones que brindan la posibilidad de revisar las propias hipótesis frente al objeto y generar nuevas significaciones del mismo. En las investigaciones didácticas, se conciben las producciones gráficas (entre la que se incluyen dibujos, esquemas, tomas de notas, etc.) como "artefactos culturales" e "instrumentos mediadores" de pensamiento, indisociablemente ligados a la elaboración cognitiva y a la interacción social. El valor de los materiales gráficos individuales es que portan los rastros de la actividad del estudiante y son un testimonio de su estado de saber en los diversos momentos del trabajo en clase. Por su parte, la circulación de los escritos entre los miembros de la clase en la elaboración grupal propicia una producción más reflexiva y generalmente más avanzada al requerir una mayor explicitación de las concepciones individuales y la confrontación de puntos de vista.

Focalizaremos en este artículo en una observación de aula realizada en un sexto grado de clase media, en la que 27 alumnos realizaron inicialmente dibujos individuales con la consigna: "Dibujen cómo piensan que se producen las noticias. No se preocupen si les parece que no dibujan bien. Nos interesa que puedan ilustrar lo que están pensando sobre este tema. Traten de dibujarlo y agregar todo lo que necesitan, por eso pueden agregar textos para explicar lo que dibujaron. Lo importante es que se entienda para que después puedan usarlo en otro momento sin olvidarse qué quisieron poner y además para poder explicarlo".

Luego de la producción individual, la docente les pidió que se reunieran en grupo para compartir su producción individual y elaborar una grupal en un afiche. La consigna fue: "Cada uno tiene que presentar a su grupo lo que dibujó y contar cómo lo pensó. Una vez que todos presentaron, debatan entre ustedes para armar en el papel afiche un nuevo dibujo que represente para todos ustedes cómo se producen las noticias". Se conformaron 6 grupos de 4 o 5 alumnos.

En este artículo nos detendremos en el análisis exhaustivo de uno de los grupos en el que participaron 5 alumnos reunidos con el propósito de compartir sus dibujos individuales, debatir sus ideas y realizar el dibujo grupal.

Tanto los dibujos individuales como la producción grupal, con sus respectivos comentarios, fueron indagados con la metodología del análisis crítico del discurso. Se establecen los minirrelatos como unidades de significación y se los analiza, en el plano icónico y lingüístico, registrando los indicadores de superficie relativos a los procesos de transformación y de transacción. Las categorías lingüísticas incorporadas a la interpretación de los datos fueron los marcadores temporales, los deícticos y los verbos.

\section{Análisis de las conceptualizaciones de alumnos de sexto grado}

Para analizar el proceso constructivo realizado por los alumnos de sexto grado en su aproximación al proceso de producción de noticias, examinamos sus dibujos, los textos con que intentaron explicarlos y el intercambio de opiniones que tuvo lugar durante la elaboración grupal. 
Al desentrañar estos datos a partir de las distintas perspectivas mencionadas, pudimos constatar que los niños realizan múltiples inferencias en su interacción asimétrica con las industrias mediáticas. Así, construyen hipótesis ${ }^{3}$ con densidad propia que funcionan como un marco organizador que les posibilita un acercamiento a la comprensión del proceso mediático. Esta construcción requiere un prolongado esfuerzo de elaboración intelectual y reorganizaciones progresivas del entramado de ideas. Como veremos, el camino no resulta lineal, sino un proceso de marchas y contramarchas en las cuales se iluminan ciertos aspectos y se mantienen opacos otros.

\section{Caminos constructivos de conceptualización de la producción mediática}

Los niños parten de una conceptualización centrada en las instancias más visibles (la distinción entre hecho y noticia, el concepto de noticia como género mediático y su circulación entre los diversos dispositivos) hacia aquellas instancias más invisibilizadas por las empresas mediáticas (procesos de producción, entendidos como procesos de transformación y transacción).

Hemos tenido en cuenta en el análisis de las producciones las dos situaciones que se desarrollaron en el aula:

1. Las producciones individuales, en las que examinamos el dibujo de cada niño y su presentación oral al grupo.

2. La producción grupal, en la que nos detuvimos en el debate generado en el intercambio de las producciones individuales y en el proceso de elaboración del dibujo grupal.

Figura 1

Dimensiones de análisis de los caminos constructivos de conceptualización de la producción mediática

\begin{tabular}{l|l}
\hline $\begin{array}{l}\text { Producciones individuales } \\
\text { (dibujos y presentación oral al grupo) }\end{array}$ & Concepto de noticia como fenómeno discursivo que circula en los medios. \\
\cline { 2 - 2 } & $\begin{array}{l}\text { Los procesos invisibles de producción de sentido: } \\
\text { a. El proceso de transformación } \\
\text { b. El proceso de transacción }\end{array}$ \\
\hline $\begin{array}{l}\text { Producción grupal (intercambio de } \\
\text { producciones individuales y proceso de } \\
\text { elaboración del dibujo grupal). }\end{array}$ & Microgénesis grupal, para percibir la captación en los medios. \\
\hline
\end{tabular}

Fuente: elaboración propia

\section{Las producciones individuales}

El concepto de noticia como fenómeno discursivo que circula en los medios

Los niños "saben" que para que haya una noticia es necesario que ocurra un acontecimiento para comentar. Este acontecimiento en bruto es algo que se produce o se ha producido. Hay un cambio en el mundo fenoménico que se manifiesta físicamente, como sucede en la producción de Paula (figura 2) ${ }^{4}$ :

3 El término hipótesis se refiere a las creencias o ideas que construyen los sujetos sobre un objeto de conocimiento para "dar cuenta de su funcionamiento", que trascienden lo observable y no se consideran conjeturas en sentido estricto (Ferreiro, 1998, p. 42).

4 Para una mejor comprensión, al lado de los gráficos se transcribe la escritura infantil utilizando la ortografía convencional. Se modificaron los nombres para preservar la identidad de los niños estudiados 
Como vemos en este gráfico y su descripción, lo primero que surge es la distinción entre ese hecho o acontecimiento en bruto $^{5}$ y la noticia o acontecimiento mediático. Paula diferencia entre "que pasa algo" y "lo pasan por la tele". Tal distinción la hallamos en las pruebas piloto en una niña de 4 años y muestra que la primera de las diferenciaciones que los sujetos realizan es entre la realidad y su representación; las noticias se asumen como el resultado de un proceso de semiotización. Esto es muy importante, porque la noticia como género marca una enorme diferencia con la ficción. Pensemos que en esta última los hechos se construyen, mientras que en la noticia el hecho queda fuera del proceso de construcción.

Los niños también representan la circulación de este discurso en una diversidad de dispositivos mediáticos, tal como puede observarse en el dibujo de Gisel, quien señala que la noticia se difunde en "todos los medios" (figura 3).

Figura 2

Dibujo individual con la consigna: ¿Cómo piensan que se producen las noticias?

Primero pasa algo muy impactante (como lo de Bariloche), luego ya sea en ese barrio o lugar haya pasado algo y alguien que lo haya visto viaja al canal o a lo que sea y le cuenta a la producción, la producción manda al móvil a filmar. Después le cuentan a la periodista/o y ahí es cuando lo pasan por la tele.

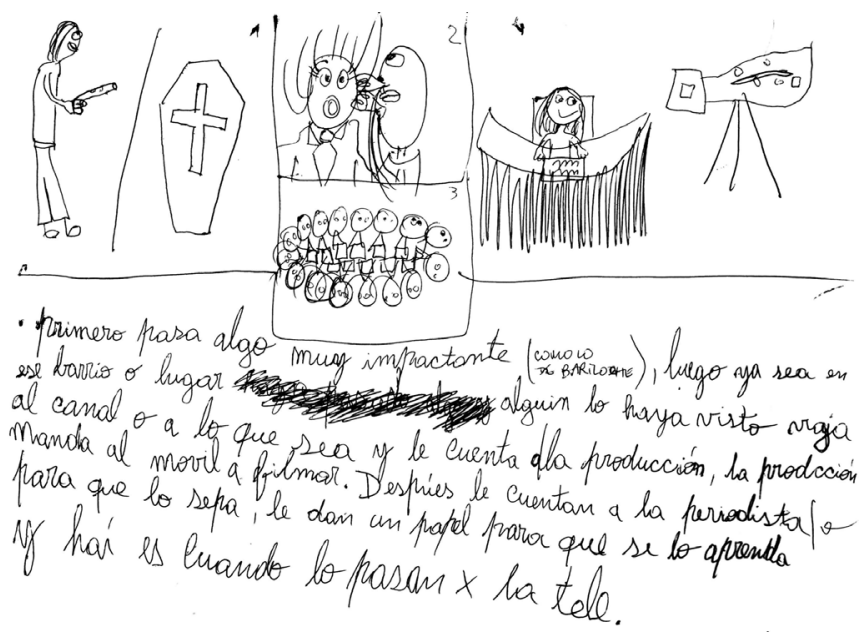

Fuente: Paula, $6^{\circ}$ grado, escuela privada, CM

Figura 3

Dibujo individual con la consigna: ¿Cómo piensan que se producen las noticias?

1. ACCIDENTE. Accidentado por un choque [muerto].

2. Escriben lo que ocurrió

3. [LA QUE ESCRIBIÓ LO QUE PASÓ]

¿Es importante la noticia?

-[JEFA] ¿A ver?

-Tome.- Sí, sí

4. [TELE] Últimas noticias

5. [TELE]

6. Y se pasa por todos los medios.

Fuente: Gisel, $6^{\circ}$ grado, escuela privada, CM

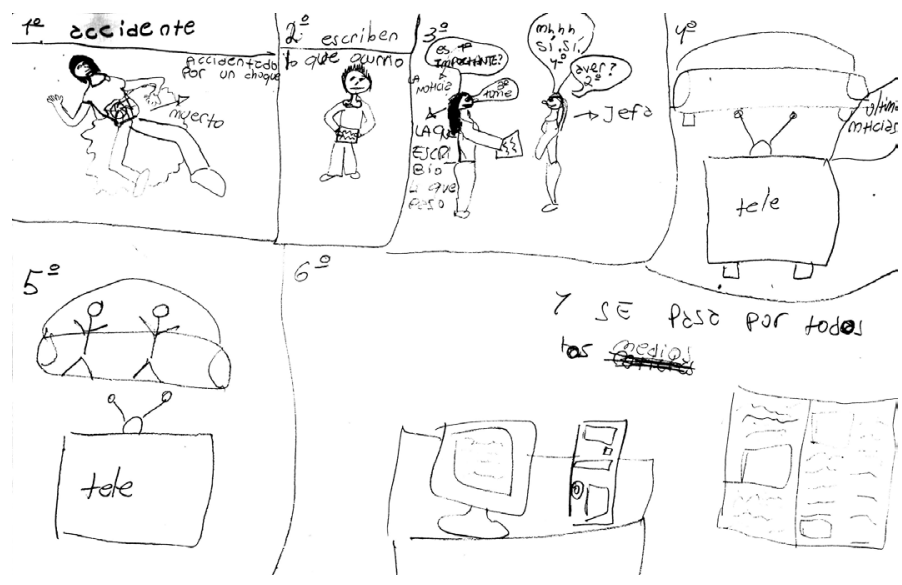

5 "Lo de Bariloche" refiere a la noticia de la erupción del volcán Puyehue, próximo a esta ciudad turística, que provocó su aislamiento por la dispersión de cenizas en la zona. Las erupciones ocurrieron entre 2011 y 2012. 
Este gráfico muestra los múltiples soportes por los que se difunden las noticias: la televisión, la computadora y hasta el diario se señalan como "medios" por donde circula la información.

De este modo, los niños se aproximan con cierta precisión a las características destacables del género noticia.

Según Patrick Charaudeau (2003), las noticias son un conjunto de informaciones referidas a un mismo espacio temático que provienen de una determinada fuente, que tienen carácter de novedad y que pueden ser tratadas de diversas maneras. Si nos detenemos en el análisis de las producciones individuales, observamos:

- Las noticias representadas refieren a un espacio temático. Cada niño ha tomado un único hecho para constituirlo como tema central: las cenizas del volcán Puyehue en Bariloche (figura 2), un choque en el que muere una persona (figura 3), otro choque de autos (figura 4), el asesinato de una chica (figura 5). Estos hechos aparecen inscriptos en el ámbito de experiencia del espacio público.

- Las fuentes están muy presentes. Se señala quién ve el hecho y quién lo transmite, y esta explicitación parece vincularse con la estrategia de producir efectos de credibilidad.

"Alguien que lo haya visto, viaja al canal o a lo que sea y le cuenta a la producción" (Paula, figura 2).

"Justo había un periodista que anota todo lo que vio" (Katia, figura 4).

- Las informaciones presentadas en las noticias tienen un carácter de novedad. Tratan de acontecimientos que se supone que otros no conocen y, junto con ello, se evalúa su importancia en relación con la distancia que media entre el momento de su aparición y el momento de la información como sucede con las cenizas del Puyehue en Bariloche tematizadas por Paula (figura 2) (potencial de actualidad), su cercanía al sujeto productor de la noticia -el periodista mencionado por Katia (figura 4) - (potencial de proximidad); su capacidad para captar la atención, el interés, el afecto del receptor, como anticipa Paula: "pasa algo muy impactante" (potencial de impregnación).

- Finalmente, como hemos visto, los niños conciben que las informaciones pueden ser vehiculizadas por diferentes medios (televisión, diario, radio e internet)

Es importante observar que los sujetos estudiados acceden mayoritariamente a las noticias por medio de la televisión, lo que parece favorecer que las conceptualizaciones acerca del género sean asimiladas al universo televisivo. De ahí que la espectacularidad permea fuertemente los modos de concebir las noticias. En Paula (figura 2), la idea de que el hecho debe ser "impactante" y la mención del "canal", el "móvil" que filma y "lo pasan por la tele" dan cuenta de la presencia del formato televisivo en su discurso. Aun cuando los niños pueden reconocer la multiplicidad de dispositivos mediáticos, la televisión es la que mayor importancia adquiere en la representación de los hechos noticiables. También es destacable que los sectores sociales más vulnerables desde el punto de vista económico grafican con mayor recurrencia la televisión como el soporte único por el cual se accede a las noticias. 
En suma, en todos los dibujos se advierte que las noticias responden a los requisitos de ser "noticiables" vigentes en los medios, aunque todavía no logran comprender que pueden ser tratadas de diversa manera. Así, Gisel (figura 3) piensa que noticia la que "se pasa" en los diferentes dispositivos mediáticos es la misma. No concibe un procesamiento particular realizado en cada medio de acuerdo con los intereses, los puntos de vista y las decisiones editoriales de quienes representan, tal como se analiza desde la perspectiva comunicacional. Esta conceptualización, muy frecuente en la población estudiada, parece señalar que la circulación de noticias aparece ante los ojos del sujeto mucho más temprano que la complejidad del proceso de producción noticiosa. Y esto puede deberse a que en este momento los medios convergen en el establecimiento de agendas unívocas por la feroz competencia, pero también a que, sin lugar a dudas, el proceso de elaboración por el cual las noticias advienen como tales en los diversos medios masivos es uno de los aspectos más opacados por las empresas mediáticas.

Los procesos invisibles de producción de sentido

Los procesos de producción y recepción son referidos por los niños mediante minirrelatos marcados temporalmente (figura 4):

Figura 4

Dibujo individual con la consigna: ¿Cómo piensan que se producen las noticias?

\section{AUTO-AUTO-MUJER \\ [MUJER]: - Mire la super noticia. \\ [HOMBRE, DUEÑO DEL NOTICIERO\}: - Qué bueno, la vamos a pasar por el noticiero, vamos. \\ [NOTICIERO]: Noticias de último momento.}

Fuente: Katia, $6^{\circ}$ grado, escuela privada, CM

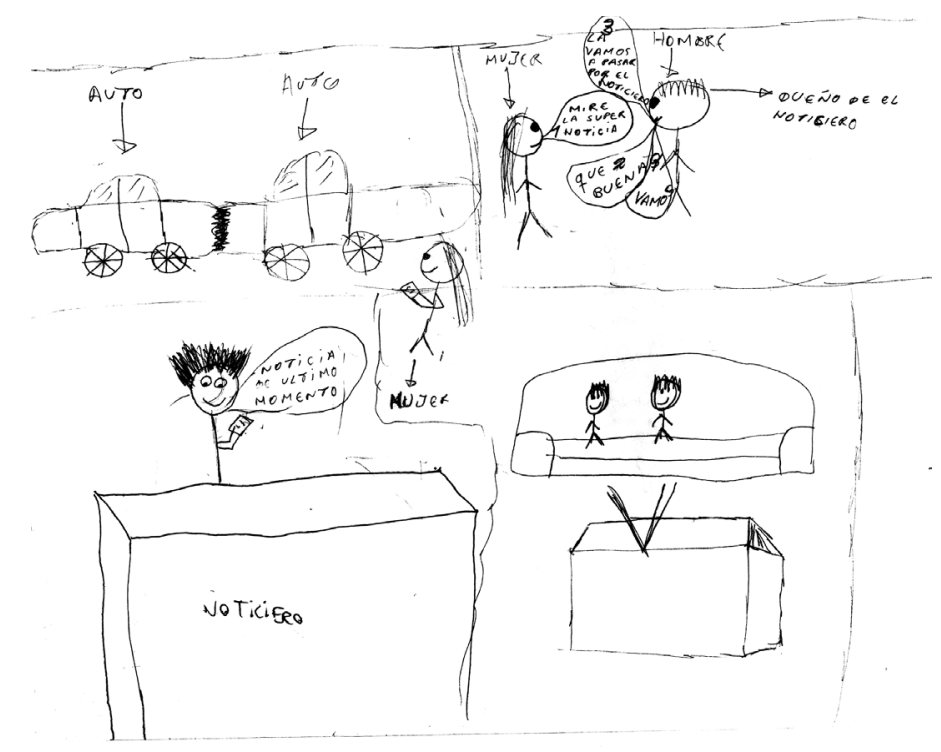

Katia (explicando al grupo): "Primero hay dos autos que están chocando y justo había un periodista que anota todo lo que vio. Después va al dueño del canal y le dice: 'Mire qué buena noticia, se trata de una supernoticia', y el jefe le dice: 'Qué bueno, la vamos a pasar por el noticiero, vamos al canal'. Y ahí le comunican al periodista y acá dice: 'Noticias de último momento' y lo pasan. Y después llega a las casas, acá ven el dibujito de la tele con el noticiero y después a la computadora".

Este minirrelato de Katia refleja con precisión la temporalidad del proceso que media entre el hecho, su difusión en los medios y su recepción: 
"primero"... ("hay dos autos que están chocando")... ("había una periodista que anota todo lo que vio")... "después" ("va al dueño del canal")... "después" ("llega a las casas" por la tele)... "después" ("a la computadora"). El proceso a su vez se remarca con verbos que indican desplazamientos (ir y llegar): "va al dueño"... "vamos al canal"... "después llega a las casas"... "después a la computadora". La temporalidad y la mención de desplazamientos de los actores y de la noticia misma, además de ser centrales en la estructura del minirrelato, parecen estar al servicio de la verosimilitud de lo expresado: el hecho se registra, se comenta, es evaluado por el dueño del canal, se comunica al periodista y llega al público por medio de la televisión y de la computadora en un tiempo y con una movilidad cuyas marcas están en el texto que despliega el proceso.

Con estos minirrelatos y los dibujos, hemos podido analizar cómo los niños conciben los procesos de transformación y transacción que median entre los hechos y el discurso.

\section{Elproceso de transformación}

Este proceso posibilita el pasaje del acontecimiento en bruto al acontecimiento mediático. En la mayoría de las producciones individuales, se observan algunos atisbos de que los niños conciben que el sujeto que se hace cargo de la transformación del hecho en acontecimiento opera sobre lo percibido para que pueda ser una noticia factible de ser interpretada como tal por un receptor. Se trata de una primera sospecha respecto de la relación entre aquello que sucede y aquello que se informa sobre lo sucedido.

En esta instancia, aparecen en los dibujos y en los comentarios dos roles centrales: el del informador y el del seleccionador (figura 5: Luciana).

Figura 5

Dibujo individual con la consigna: ¿Cómo piensan que se producen las noticias?

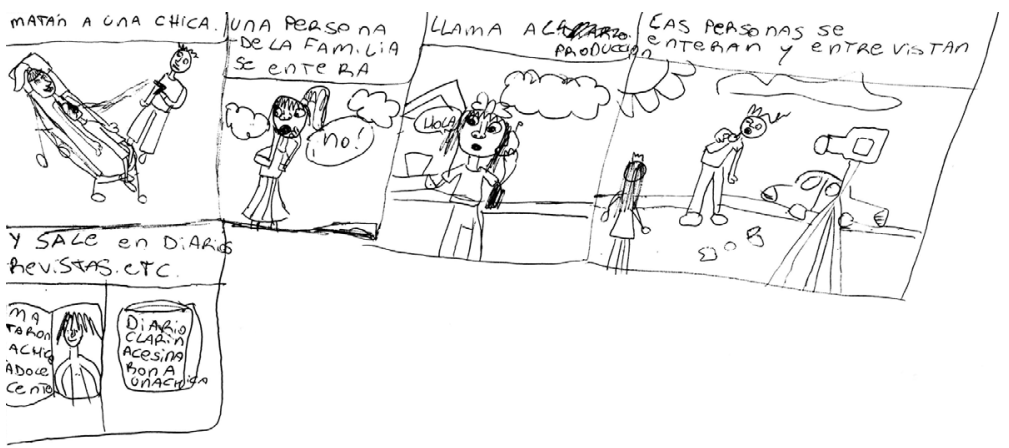

Fuente: Luciana, $6^{\circ}$ grado, escuela privada, CM

El informador puede ser testigo de los hechos (figuras 2 y 4) o puede ser llamado por los testigos (figuras 3 y 5) para que los capture fielmente mediante diversos dispositivos (móvil, cámaras) y describa y narre los acontecimientos. El informador ocupa así un lugar central en el proceso de transformación del mundo a comentar en mundo comentado y engarza, de algún modo aún poco observable para los niños, el espacio público — donde se instala el acontecimiento - con el espacio privado de la edición.

Pero el selector que aparece corporizado en un jefe que decide acerca del interés que reviste el acontecimiento actúa en el espacio privado. En el dibujo de Gisel (figura 3), se menciona una "jefa" que evalúa la
Matan a una chica

Una persona en la familia se entera. iNo!

Llaman a la producción. Hola.

Las personas se enteran y entrevistan

Y sale en el diario, revistas, etc. [MATARON A CHICA DOCENTE] [DIARIO CLARÍN. ASESINARON A UNA CHICA]. 
importancia de la noticia como tal para que se transmita en los medios. Esto mismo puede notarse en el dibujo de Katia (figura 4) en que también se observa una figura, la del "dueño del noticiero" (que es concebido luego como "jefe"), con la función de demarcar que se trata de "una supernoticia" y decidir que "la vamos a pasar por el noticiero". La presencia de este jefe o dueño "decisor" constituye un progreso conceptual significativo, ya que puede ser una primera aproximación al proceso de selección de contenidos en el campo de la información mediática y a los poderes que se ponen en juego en esta instancia (véase la referencia a la producción del discurso informativo desde la perspectiva comunicacional).

En conceptualizaciones más primitivas, no aparece una instancia de producción diferenciada, se presenta el hecho que automáticamente se convierte en noticia. La comprensión de que hay "algo/alguien" entre la captura informativa y aquello que se dará a conocer como noticia resulta un avance decisivo en la reconstrucción de los procedimientos de producción noticiosa. Se comienza a pensar que hay una serie de personas y procedimientos en el medio que organizan ese pasaje entre acontecimiento y noticia. Hay periodistas informadores y "dueños de noticiero" o "jefes" que tienen diferentes responsabilidades frente a lo que se publica.

De modo que, aunque no lo explicitan ni justifican claramente, aparece un sujeto con poder que adopta criterios (la actualidad, la proximidad y la importancia del hecho) vinculados con la selección y la edición del material, lo que pone en evidencia un atisbo de organización social, jerárquica. Desde su lugar de poder, el "jefe" es concebido como quien tiene la capacidad de discernir aquello que merece ser publicado, aunque todavía es concebido con una mirada personalizada.

Finalmente, es importante advertir que en todas las producciones individuales hay cierta concepción unidireccional del proceso productivo de noticias. Siempre hay un pasaje del hecho noticiable al hecho informativo (en Katia, el choque de autos real pasa a "noticias de último momento"). Se piensa el proceso productivo como una cadena de eslabones que parte de la aparición del suceso y termina con la transmisión a los ciudadanos. No hay una decisión editorial previa acerca de qué hechos serán los cubiertos según los intereses que alberga la empresa.

\section{Elproceso de transacción}

Este proceso es el que interviene en el pasaje del mundo comentado al mundo interpretado. El receptor entra en escena.

En los dibujos, advertimos que se representa un receptor pasivo cuyo rol escénico es recibir los textos e imágenes que le llegan primordialmente por la televisión (ver figuras 3 y 4). Sin embargo, los niños no parecen aproximarse pasivamente a los medios.

La evidencia de su punto de vista como receptores es justamente la representación de la instancia de selección que ya hemos analizado. Al ser practicantes sociales de los medios, frente a la constatación de que suceden muchas más cosas en la realidad que las que son informadas en las noticias, los chicos comienzan a inferir que hay una actividad de selección que es básica: definir qué hecho es "importante" (noticiable) y cuál no lo es. Pero también descubren que mediante la selección se ejerce el poder de hacer visibles algunos hechos e invisibilizar otros. Esto muestra que los niños han comenzado a desplazar tímidamente del centro de la escena la posición ingenua de creer que la noticia es reflejo de la realidad, y están dando sus primeros pasos hacia la lectura crítica de los medios.

De este modo, el primero de los procesos que parece ser visible para los niños en la instancia de producción remite a la definición de 
aquello que se publica en los medios. El "jefe" y los periodistas, más genéricamente, cumplen el deber de informar los hechos de la realidad y por tanto, tal selección solo asume cierta economía en el tratamiento de la información, dado que no se puede abarcar la totalidad de los acontecimientos del mundo. Asumen un lugar benefactor, donde predomina la función informativa de los medios (Perelman, Estévez, Ornique, LópezBroggi \& Bertacchini, 2014).

\section{La microgénesis grupal. Percibir la captación en los medios}

Hasta aquí nos referimos a la producción realizada por cada niño en su dibujo y a la descripción oral efectuada al presentarlo al pequeño grupo. En este apartado, deseamos presentar lo sucedido cuando los niños interactuaron con la consigna de debatir sus puntos de vista y ponerse de acuerdo en la construcción de un nuevo dibujo a presentar frente al grado completo. La importancia de esta instancia de interacción entre pares se revela en los nuevos aspectos que presenta el producto grupal conseguido y también en los diálogos suscitados entre ellos a partir de la discusión sobre lo que cada uno había dibujado.

Veamos la producción final del grupo (figura 6) para examinar las novedades que aparecen.

Figura 6

Dibujo grupal con la consigna: ¿Cómo piensan que se producen las noticias?

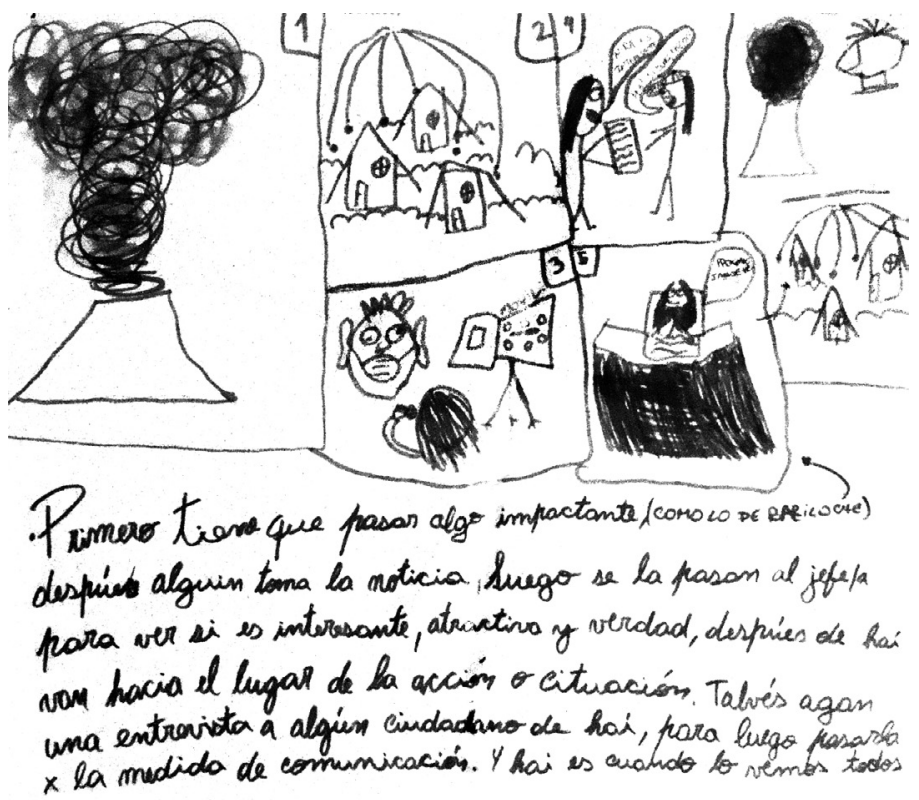

Fuente: Paula, Gisel, Katia y Luciana. $6^{\circ}$ grado, escuela privada, CM

La noticia, al igual que en los dibujos individuales, se inicia con el impacto de un hecho. La conceptualización que se sostiene es la de que el peso propio de los acontecimientos es el que provoca la noticia. También aparece la figura del "jefe" que define si el material es noticiable.

La novedad se presenta en las condiciones que se plantean para esa definición: la noticia debe ser "interesante, atractiva y verdad". Estos
Primero tiene que pasar algo impactante (como lo de Bariloche). Después alguien toma la noticia. Luego se la pasan al jefe/a para ver si es interesante, atractivo y verdad. Después de ahí van hacia el lugar de la acción o situación. Tal vez hagan una entrevista a algún ciudadano de ahí, para luego pasarla por la medida de comunicación. Y ahí es cuando lo vemos todos. 
aspectos exceden en mucho las caracterizaciones de la noticia que veníamos señalando en el análisis de los productos individuales y comienzan a orientarse en la visibilización de aspectos claves en la lectura crítica de noticias: la posibilidad de advertir la captación que los medios tratan de ejercer sobre las audiencias a la hora de informar ("interesante y atractiva") y la cuestión de la "verdad".

Nos preguntamos por tanto: ¿qué ocurrió en el intercambio de los sujetos que promovió esta aparición de novedad en la consideración de las noticias?

Para rastrear el proceso de construcción que condujo a estos logros, es preciso detenernos en algunos diálogos que se suscitaron entre los chicos. Parece que tales interacciones fueron generando tomas de conciencia respecto de aspectos de las noticias ausentes en los dibujos individuales, a partir de las cuales el dibujo grupal se presenta enriquecido.

Paula: Sí, igualmente Katia después dijo como que todo el tiempo, o sea, pasaba algo y había un periodista pero no siempre hay un periodista.

Katia: Bueno, hay que imaginar.

Paula: Porque si no también, suponete, cuando muere alguien o hay un asalto... ¿vieron eso que pasó que no sé quién se casó y el mismo día que se casó le sacaron todo de la casa o algo así?

Lucía: Luisana Lopilato6.

Paula: Pero entonces, como que hay muchas cosas que pasan por la tele que pasan más por los famosos. Sí, suponete que alguno de nosotros cinco, no sé, Gisel es famosa, entonces (dirigiéndose a Gisel) a vos te matan ¿entendés? entonces sí va a importar eso y lo van a filmar. José es un señor cualquiera, como todos y lo matan... eso pasa todo el tiempo en la calle. Y tal vez ahora hay una persona que se está muriendo y no lo pasan por ningún lado.

José: Yo agregaría algo que no sé si ustedes agregaron, yo diría que agreguemos la parte que examinan sobre de quién se trata y cuánta importancia tiene la noticia.

Paula: Porque tal vez también hay una lista de espera (se ríen). (Comienza a actuar con una lapicera como si fuese un micrófono) En el 2007 ha muerto una persona... pero está en la lista de espera...

¿De qué hablan los niños? Están ocupados en un aspecto que no termina de aparecer con claridad en los dibujos individuales: la cobertura del hecho. ¿Cómo llegan los periodistas al lugar de los hechos? ¿Cubren todos los hechos que acontecen o algunos? Lo novedoso en la conversación de estos niños es la comprensión de una nueva instancia de selección mediática (además de la que trajeran en sus dibujos individuales) que actuaría antes de la decisión de publicar o no una noticia. Se trata de una operación inicial del proceso de producción en la cual se definiría la posible "cobertura informativa", esto es, si lo que acontece podría llegar a los medios convertido en noticia. Esta selección de los hechos a cubrir, como se ve, recién se advierte en el diálogo sostenido por el grupo y no en sus producciones individuales, lo que evidencia la mayor complejidad de sostener tal dispositivo en la construcción de la noticia. La posibilidad de reconocer que hay una intención de "noticiar" cierto suceso y de dejar otro fuera del tratamiento mediático compromete seriamente la mirada

6 La noticia de la actriz Luisana Lopilato refiere a una situación de robo que sufrió mientras se desarrollaba su fiesta de casamiento. 
ingenua según la cual muchos niños plantean que los periodistas están donde suceden las noticias, a veces "mágicamente" coincidiendo con los hechos, en otras ocasiones llegando en "helicóptero" con la policía o siendo llamados por la gente.

De este modo, los niños están empezando a advertir que la finalidad informativa de los medios entra en tensión con la de "captación". Los medios deben atraer público y, por ello, parte de las decisiones que se toman en las empresas mediáticas tiene esta intencionalidad como horizonte de logro. Al "lector modelo", a las "audiencias" televisivas se los construye desde el inicio del acto comunicativo al considerar aquello que desean consumir.

Leer críticamente implica ir develando lentamente este propósito persuasivo de los medios, que pone en tensión el carácter informativo que los niños consideran inicialmente el único presente en la comunicación mediática. Por ello, resulta altamente significativo que, cuando, a partir de este diálogo grupal, los chicos llegan a reconocer que hay una selección de los hechos a cubrir (y por tanto atisban la cuestión de la captación mediática) pueden caracterizar que las noticias deben ser "interesantes" y "atractivas". La noticia tiene que captar el interés del receptor ("interesante") y para ello piensan en el privilegio de lógicas ficcionales que giran más en torno de la verosimilitud de los hechos pues los personajes de la información cumplen programas narrativos y reciben descripciones y propiedades específicas para atraer la atención del público ("atractivo").

Claro que, una vez que se visibiliza este polo de la captación, aparece con fuerza un requerimiento que antes (en la génesis de estos procesos) aparecía garantizado por el reflejo entre noticia y hecho; nos referimos a la cuestión de la "verdad". Parece que, en los chicos, la necesidad de requerir lo verdadero de una noticia adviene cuando se reconoce que no todo acontecimiento se reconoce como noticiable y que, en su demarcación como tal, es necesario atender los intereses del público. De algún modo, los niños perciben que el contrato mediático del discurso de la información opera a partir de un pacto de verdad con sus receptores y la condición para que se realice es el establecimiento de la dimensión veredictiva del discurso, mediante una compleja trama de estrategias discursivas de referencialidad y utilización de fuentes textuales.

\section{A modo de cierre y apertura}

El presente artículo intenta avanzar en dos líneas: por un lado, en el análisis de datos empíricos y por el otro, en la interpelación a diversos campos disciplinares en la configuración del estado del arte. Esta última línea resulta imprescindible en el tratamiento de un fenómeno tan complejo como novedoso: el problema de las pantallas y los medios masivos de comunicación. Por ello, en la primera parte del artículo, presentamos conceptualizaciones surgidas en diversos marcos: teorías de la comunicación, análisis del discurso, sociología de la cultura, teoría del periodismo, entre otras, además de los propios de la psicología y la educación que constituyen el campo específico en el cual se ubica la investigación. Este esfuerzo por comprender la naturaleza del objeto social desde los marcos disciplinares que lo estudian (y no solo desde la descripción de las interacciones del sujeto) constituye sin dudas un aspecto de interés del presente estudio.

Respecto del material empírico presentado, podemos decir que el análisis muestra dos instancias de producción de los alumnos ante la consigna: ¿cómo piensan que se producen las noticias? En la instancia individual, en la que se analizaron los gráficos y la explicación dada por los niños, se pusieron en evidencia conceptualizaciones que ya habíamos encontrado en indagaciones anteriores. El concepto de noticia como fenómeno discursivo que circula en los medios, y atisbos de comprensión de los procesos de transformación (intermediación de las figuras del informador y del selector) y de transacción (el saber que hay un sujeto que tiene el poder de hacer visibles ciertos hechos e invisibilizar otros).

La principal contribución de este trabajo aparece en el examen de la producción grupal. La interacción sociocognitiva generada ante la propuesta de elaborar un dibujo que representara el acuerdo entre sus puntos de vista los condujo a un comienzo de toma de conciencia de que los medios no solo ejercen una acción informativa. Descubren, en los diálogos que sostienen alrededor de casos concretos, que la intencionalidad de captación tiñe desde el inicio el proceso productivo. Esto los conduce a un inicio de comprensión de la existencia de otras lógicas (más próximas a las ficcionales) en el entramado de las noticias y a preguntarse por la "verdad" de las afirmaciones que circulan en los medios.

Al ser el presente un estudio exploratorio, sumado a la resumida muestra de esta indagación, no es posible realizar generalizaciones más allá de casos similares en circunstancias afines. No obstante, este estudio ofrece hipótesis y categorías de análisis que podrán ponerse a prueba en futuras investigaciones. Los aportes realizados en este trabajo son, por un lado, una nueva evidencia empírica de la enorme dificultad de comprender un objeto que tiene al sujeto como "blanco" de su acción, como sucede con todos los conocimientos sociales. Pero también, el haber identificado cómo las perspectivas iniciales de los alumnos pueden transformarse a partir de las propias 
interacciones entre pares, en las cuales comparten y confrontan sus hipótesis en relación con el dispositivo mediático.

Las futuras líneas de investigación se dirigen en dos sentidos. En primer lugar, explorar las interpretaciones de los estudiantes en situaciones de lectura de noticias en diversos soportes (papel y pantallas) para indagar en profundidad las conceptualizaciones que subyacen a sus lecturas. Y en segundo lugar, a partir del análisis de los datos obtenidos, diseñar y poner a prueba situaciones didácticas dirigidas a promover la lectura crítica de noticias.

Hasta el momento, sabemos que la conceptualización del universo mediático requiere un camino prolongado de construcción en el cual resultan cruciales las oportunidades que encuentren los sujetos de participar en prácticas sociales mediadas por interpretantes que propicien la reflexión sobre esos procesos. Y suponemos que la escuela puede ser un espacio propicio para generar condiciones que permitan visibilizar aquellos aspectos más opacos del artefacto mediático y que conduzcan a revisar las representaciones sociales que pueden permanecer cristalizadas en una lectura ingenua de los mismos.

\section{Sobre las autoras}

Flora Perelman es doctora en psicología y especialista en escritura y alfabetización. Docente de psicología y epistemología genética, Universidad de Buenos Aires, UBA. Autora de El resumen sobre el papel: condiciones didácticas y construcción de conocimientos, Enseñando a leer en internet: pantalla y papel en las aulas, coeditora de Las TIC en la escuela, nuevas herramientas para viejos (y nuevos) problemas.

Débora Nakache es licenciada en psicopedagogía. Profesora adjunta regular de psicología educacional, Universidad de Buenos Aires, UBA. Investiga y publica acerca de las relaciones entre pantallas, infancias y aprendizajes. Coordina desde 2001 el Programa "Medios en la escuela" del Ministerio de Educación del Gobierno de la Ciudad de Buenos Aires, GCBA. Organiza "Hacelo Corto", festival de cortometrajes producidos por niños y jóvenes que se realiza desde hace doce años.

Gabriela Rubinovich es licenciada en ciencias de la comunicación. Profesora de enseñanza primaria. Jefa de trabajos prácticos de didáctica de la comunicación y prácticas de residencia y teoría de los medios y la cultura en la Universidad de Buenos Aires, UBA. Coordinadora del programa medios en la escuela y especialista del área de currícula del Ministerio de Educación del Gobierno de la Ciudad de Buenos Aires, GCBA.

María Elena Rodríguez es licenciada y profesora en letras, especializada en lingüística, egresada de la Universidad de Buenos Aires, UBA. Dicta el seminario Sociolingüística y Educación Lingüística Crítica en la Maestría de Alfabetización y Escritura, Universidad Nacional de La Plata, UNLP. Se desempeña como asesora lingüística del proyecto Escuelas de Innovación-Conectar Igualdad. Área lengua y literatura. Investiga temas vinculados con lingüística aplicada a la enseñanza de la lengua materna. Autora de diversas publicaciones sobre el desarrollo del lenguaje en contextos de aprendizaje de la lectura y escritura.

María Jimena Dib es licenciada y profesora en letras. Especialista en procesos de lectura y escritura, Universidad de Buenos Aires, UBA-UNESCO). Cocoordina el subnúcleo de lecturas y escrituras de la Escuela de Capacitación Docente (CePA) Buenos Aires). Se desempeña como especialista en lengua para la dirección de currícula en la misma ciudad y como docente de didáctica de la lengua y de prácticas de la enseñanza en varios profesorados públicos de educación primaria. Es autora de diseños y documentos curriculares jurisdiccionales del área. 


\section{Referencias}

Aruguete, N. \& Zunino, E. (2010). El encuadre de las noticias. En Lila Luchessi (comp.). Nuevos escenarios detrás de las noticias. Agendas, tecnologías y consumos, 37-50. Buenos Aires: La Crujía.

Cassany, D. (2006). Tras las líneas. Sobre la lectura contemporánea. Barcelona: Anagrama.

Castedo, M. (2007). Notas sobre la didáctica de la lectura y la escritura en la formación continua de docentes. Lectura y Vida. Revista Latinoamericana de Lectura, 28 (2), 6-19. Disponible en: http://www. lecturayvida.fahce.unlp.edu.ar/numeros/a28n2/28_02_Castedo.pdf

Castorina, J. A. (2010). Psicología de los conocimientos sociales en los niños y teoría de las representaciones sociales. En José Antonio Castorina \& Mario Carretero (eds.). La construcción del conocimiento histórico. Enseñanza, narración e identidades. Buenos Aires: Paidós.

Charaudeau, P. (2003). El discurso de la información. La construcción del espejo social. Barcelona: Gedisa.

Delval, J. (2001). Descubrir el pensamiento de los niños: introducción a la práctica del método clínico. Barcelona: Paidós.

Dijk, T. van (1999). Ideología. Una aproximación multidisciplinaria. Barcelona, Buenos Aires: Gedisa.

Dijk, T. van (ed.) (2000). Estudios del discurso. 2 vols. Barcelona, Buenos Aires: Gedisa.

Dijk, T. van (ed.) (2003). Ideología y discurso. Una introducción multidisciplinaria. Barcelona: Ariel.

Eco, Umberto (1965). Apocalípticos e integrados. Barcelona: Lumen.

Ferreiro, E. (1998). Información disponible y procesos de asimilación en los inicios de la alfabetización. En Alfabetización, teoría y práctica, 4183. México: Siglo XXI Editores.

García-Debanc, C.; Laurent, D. \& Galaup, M. (2009). Les formulations des écrits transitoires comme traces du savoir en cours d'appropriation dans le cadre de l'enseignement des sciences à l'école primaire. Pratiques, 143-144, 27-50. Disponible en: http://pratiques.revues.org/1384

Gilly, M. (1988). Interacciones entre pares y construcciones cognitivas: modelos explicativos. En Anne-Nelly Perret-Clermont \& Michel Nicolet (eds.). Interactuar y conocer: desafíos y regulaciones sociales en el desarrollo cognitivo, 23-32. Buenos Aires: Miño y Dávila.

Luchessi, L. (2010). Nuevos escenarios detrás de las noticias. En Lila Luchessi (comp.). Nuevos escenarios detrás de las noticias. Agendas, tecnologías y consumos. Buenos Aires: La Crujía.

Mastrini, G. \& Becerra, M. (dirs.) (2006). Periodistas y magnates. Estructura y concentración de las industrias culturales en América Latina. Buenos Aires: Prometeo. Disponible en: fndc.org.br/download/periodistasy-magnates.../periodistas-y-magnates.pdf

Moscovici, S. (1961). La psychanalyse, son image et son public. Paris: Presses Universitaires de France, PUF.

Murià, I. (1995). La noción de religión en los niños y adolescentes: estudio comparativo entre mexicanos y españoles. Tesis doctoral. Madrid: Universidad Autónoma de Madrid. Departamento de Psicología Evolutiva y de la Educación. Disponible en: http://www.uaq.mx/psicologia/ mec/MEC\%20-\%20UAQ/3.\%20Personal\%20Academico/3.2\%20 Lineas $\% 20$ de\%20 Generacion $\% 20 y \% 20$ Aplicacion $\% 20$ del $\% 20$ Conocimiento/3.2.2\%20Produc. $\% 20$ Academica $\% 20$ por $\% 20$ integrante\%20NAB/3.2.2.5\%20Dr.\%20Juan\%20Delval\%20Merino/ 1.\%20Documentos\%20Varios/Tesis-1.pdf 
Perelman, F. \& Nakache, D. (2011). Lectura crítica de las noticias en los medios: caminos cognitivos de niños y niñas en contextos escolares. Memorias III Congreso Internacional de Investigación y Práctica Profesional en Psicología. Tomo 1, 418-422. Buenos Aires: Facultad de Psicología, Universidad de Buenos Aires, UBA. Disponible en: http:// www.aacademica.com/000-052/517.pdf

Perelman, F.; Nakache, D. \& Estévez, V. (2012). Conceptualizaciones infantiles sobre la producción de noticias. XIX Anuario de Investigaciones, 19 (tomo I), 363-373. Buenos Aires: Facultad de Psicología, Universidad de Buenos Aires, UBA. Disponible en: http://www.scielo.org.ar/ scielo.php?script=sci_arttext\&pid=\$1851-16862012000200002

Perelman, F.; Estévez, V.; Ornique, M.; López-Broggi, O. \& Bertacchini, P. (2014). De la lectura ingenua a la lectura crítica de las noticias mediáticas en niños. XX Anuario de Investigaciones, 20 (tomo I), 181-193. Buenos Aires: Facultad de Psicología, Universidad de Buenos Aires, UBA. Disponible en: http://www.scielo.org.ar/scielo.php?script=sci arttext\&pid =S1851-16862013000100017

Perret-Clermont, A.-N. (1984). La construcción de la inteligencia en la interacción social: aprendiendo con los compañeros. Madrid: Visor (Aprendizaje).

Piaget, J. (1926). La representación del mundo en el niño. Paris: Presses Universitaires de France, PUF.

Piaget, J. \& García, R. (1982). Psicogénesis e historia de la ciencia. México: Siglo XXI.

Reese, S. D. (2001). Prologue, Framing Public Life: A Bridging Model for Media Research. En Stephen D. Reese, Oscar H. Gandy \& August E. Grant (eds.). Framing Public Life: Perspectives on Media and our Understanding of the Social World, 7-32. Mahwah, New Jersey: Lawrence Erlbaum Associates.

Rosa, A. de (1987). The Social Representation of Mental Illness in Children and Adults. En Willem Doise \& Serge Moscovici (eds.). Current Issues in European Social Psychology, Vol. 2, 47-138. Cambridge: Cambridge University Press.

Rosenblatt, L. M. (2002). La literatura como exploración. México: Fondo de Cultura Económica, FCE.

Teberosky, A. (1982). Construcción de escrituras a través de la interacción grupal. En Emilia Ferreiro \& Margarita Gómez-Palacio (eds.). Nuevas perspectivas sobre los procesos de lectura y escritura, 155-178. México: Siglo XXI.

Villaoslada, E. (1997). Origen y desarrollo de las ideas y actitudes infantiles acerca de la desigualdad social. Tesis doctoral. Madrid: Universidad Autónoma de Madrid. Departamento de Psicología Evolutiva y de la Educación.

Williams, R. (1977). Marxismo y literatura. Buenos Aires: Península.

Wodak, R. \& Meyer, M. (comps.) (2003). Métodos de análisis crítico del discurso. Barcelona: Gedisa. 